\title{
INVESTIGATION OF PROVISION AND UTILIZATION OF LABORATORY FACILITIES AND STUDENTS' PERFORMANCE IN PRACTICAL BIOLOGY IN GOMBE STATE, NIGERIA
}

\author{
Y. M. KAMAR \\ Department of Science \& Vocational Education, Usmanu Danfodiyo University, Sokoto, Nigeria. \\ DANJUMA SHEHU IBRAHIM \\ Department of Education, Gombe State University, Gombe, Nigeria.
}

\begin{abstract}
The study investigated the provision and utilization of laboratory facilities as a function of students' performance in practical biology among the senior secondary schools in Gombe State. Three hundred and seventeen (317) SS III students and their biology teachers were used as sample for the study. Three instruments, Biology Laboratory Facilities Inventory, Biology Laboratory Facilities Utilization Scale and the Students' Test of Practical Biology were used to collect data. The data collected were expressed in percentages (\%) and analyzed using Analysis Of Variance (ANOVA) and the Statistical Package for Social Sciences (SPSS). The results revealed that there was a deficiency in the availability and utilization of biology laboratory facilities. It also revealed that there was significant relationship between availability and utilization of facilities with students' performance in practical biology at 0.05 level of significance. The study recommended that the state ministry of education needed to provide the necessary practical facilities for schools offering biology. It should also encourage the training of teachers as well as support them to attend and participate in workshops and seminars.
\end{abstract}

\section{Introduction}

Science subjects have become very important parts of the school curriculum in Nigeria. The three most popular subjects studied in Nigerian secondary schools are Biology, Chemistry and Physics. Practical work is the backbone of effective science teaching and learning. It has been repeatedly emphasized that scientific enterprise is an activity packed one, involving continuous exploration and verification of facts (Alebiosu, 2003).

Science is learnt by doing and dealing with investigation of nature, so the different schools curricular could adequately provide for practical activities at every stage of learning experiences. Science is experimentation and its teaching especially focuses on making students learn through the workings of hands, brain and the heart (Alebiosu, 2003). Biology however is known to have the largest population of students in schools. This is obvious from the students' enrolment for their final examinations in Nigerian secondary schools (Ndu, 1980). The students' performances at external examinations organized by both West African Examinations Council (WAEC) and National Examinations Council (NECO) do not however show a positive relationship between the desire to study biology and the students' competences at the end of their studies (Sadiq, 2007).

However, education, the world over, has been identified as one of the vehicles for the development of any nation. It is also an instrument for creating awareness and instrument for future development of any individual, while school is a formal place where learners are being taught and inculcated with various knowledge and skills necessary for capacity development which eventually lead to national development (Yakubu, 2005). 
The structure of Biology as a science subject is made up of two components, namely content and methods or practical techniques (Mogbo, 1992). In learning this subject, therefore, a pupil is said to be familiar with, and have a good grasp with the basic scientific concepts and principles. Also, abilities and skills with respect to basic scientific processes of observation, classification, measuring, collection and interpretation of data, inferring, application, hypothesizing and experimentations are supposed to be acquired in the course of learning Biology (Abdullahi, 1982). It is in the domain of methods of learning the science of Biology that these scientific processes are learned.

Science and technology which are often recognized as the basic tools for industrialization and national development could bring economic and social happiness by providing employment and improving the welfare of the citizenry (Oyekan, 1993). For the development of individuals and social life natural sciences were included in secondary education for specialized professional studies which will also have a positive effect on technological growth The instructional value of graphical illustrations lies generally in their capacity to attract attention and convey certain types of information in condensed form (Onasanya \& Adegbija, 2007). Similarly, Hofstein and Mamlok-Naaman (2007) pointed out that both the content and pedagogy of science learning and teaching are being scrutinized and new standards intended to shape and rejuvenate science education are emerging. In Biology, theory and practical demonstration of knowledge are closely linked in that deficiency in one aspect adversely affects competence in the other.

Science has become a very important part of Nigerian secondary school curriculum. The more popular subjects are Chemistry, Physics and Biology. Over the years the enrolments of students in public examinations conducted by the West African Examination Council (WAEC) has shown that Biology is the most preferred to other science subjects (Sorunke, 1982).

The examinations organized by the two bodies that organize SSCE examinations i.e. West African Examinations Council (WAEC) and the National Examinations Council (NECO) demand that candidates respond to questions on both theoretical and practical knowledge. The results of such examinations have shown that the candidates probably lack the competence expected of them since the rate of failure in the two organized exams is relatively high (Sadiq, 2007).

It is necessary to note that mastery of practical techniques in Biology has a relationship with availability of equipment and ability to use such equipment and other laboratory facilities (Mogbo, 1992). This is so because the processes and skills in Biology can be carried out and mastered by students using appropriate and adequate laboratory facilities (Pritchard, 1990). The role of science is being threatened by poor performance of students in practical tasks in internal and external examinations (Balogun, 1986). People however, have given various reasons for this poor performance of students and these range from inadequate resources, non-availability of laboratory facilities, large classes, in adequate time allocation, poor science teaching due to teachers' incompetence and poor commitment to students' poor attitude to learning (Sorunke, 1982). 
SER Vol. 16 (1): June 2015 


\section{Objectives of the Study}

The objectives of this study are to:

i. Establish whether secondary schools in the area of study possess sufficient Biology laboratory facilities.

ii. Establish the extent to which teachers make use of laboratory facilities.

iii. Find the relationship between utilization of laboratory facilities and students performance in practical Biology.

\section{Research Design}

A survey research design was used for the study. A survey is a data collection technique in which information is gathered from individuals called respondents, by having them respond to questions. It is not concerned with characteristics of individuals as individuals. It is concerned with the generalized statistics that results when data are abstracted from a number of cases.

\section{Population of the Study}

The population consists of all the Biology teachers in all the selected secondary schools under study in Gombe State, which comprises three educational zones. From the educational zones, a random sampling was used in selecting the schools for the study and six (6) Local Governments were selected from the three educational zones using the random sampling. In each of the selected Local Governments, twenty one (21) schools were selected using the same random sampling. There were eighty six public secondary schools in Gombe state, eight science, five science and technology and seventy four arts based. Three hundred and seventeen students were used for the study, in each of the selected schools an arm of SS3 class was selected at random. Data obtained from the sample schools indicated that there was an average of 80 students per class. Details of the samples selected are shown in Table 1 ahead.

\section{Instrumentation}

The following instruments were used for data collection.

a. Biology Laboratory Facility Inventory (BLFI)

b. Biology Laboratory Facility Utilization Rating Scale (BLFU)

c. Test on Practical Biology (TPB)

The instruments were designed by the researcher; they were designed in such a way that the materials in each category were listed as to the degree of their availability and their level of utilization. The Biology Laboratory Facility Inventory (BLFI) has eighty three (83) items. Respondents were requested to indicate a tick regarding the state of condition of such materials as follows: (a) not available, (b) available but not enough or (c) available and adequate, as the case maybe. The Biology Laboratory Facility Utilization Rating Scale 
(BLFU) with the same number of eighty three (83) items, respondents indicated the level of the facilities utilization as follows: (a) never used before, (b) used but not all the time, (c) used for examination purposes only, (d) used for every lesson or not accessible and (e) used only by teachers. For the test of practical biology instrument NECO and WAEC alternative to practical biology questions were adopted for the purpose of testing the students' knowledge on practical Biology. Details of these instruments were given at the end of the report as appendix A, B and C. The designed instruments were validated by experts and professionals in Science and Vocational Education Department of Usmanu Danfodiyo University Sokoto. Based on the comments and advice from these experts, adjustments and modifications were made where necessary, especially concerning the avoidance of ambiguities and the difficulties that respondents might have in completing the instruments. The final, validated instruments emerged after modification. The reliability of the instruments were determined by way of test-retest method. A pilot test was conducted in three schools. A school was selected from each of the three educational zones for the pilot study. The students were also administered with the students' test of practical Biology instrument. In order to have accuracy the Cronbach Alpha Coefficient was used in determining the reliability of the Biology laboratory facility inventory (BLFI). The reliability yielded an r-value of 0.87 likewise the Biology laboratory facility utilization (BLFU). The same Cronbach Alpha Coefficient was used to determine its reliability in which a reliability coefficient of 0.79 was obtained. Pearson Correlation Coefficient was used to obtain the rvalue of the test-retest of the practical Biology at significant value of 0.05 levels.

\section{Results and Findings}

The data of this study were collected using a survey research design. Furthermore, the study involved the use of three types of research instruments; biology laboratory facility inventory, biology laboratory facility utilization and test of practical biology to collect relevant data. The data yielded by these instruments were analyzed using the statistical package for social sciences (SPSS). The results indicated that there were significant relationships between availability and utilization of biology laboratory facilities on the one hand and students' academic achievements on the other. The investigation also revealed that most of the schools lacked biology laboratory facilities while those schools with few such facilities did not make proper use of them.

The investigation further revealed that students with higher percentage of biology laboratory facilities performed better than students with fewer facilities. This finding indicated that there was a relationship between availability of laboratory facilities and students' performance in practical biology.

Furthermore, students that made use of available facilities performed better than those with fewer facilities, even though it was observed that few among the students with fewer facilities made use of them. There was therefore, a relationship between utilization and students' performance in practical biology.

To get the relationship between availability, utilization and students' performance, the unit score-per-school was obtained. The overall scores were used to rate schools' level of 
availability and utilization of biology practical facilities. The weighted scores of availability and utilization were based on the following criteria.
a. Generally not available or not utilized
b. Fairly available and utilized
c. Generally available and utilized

Each school was expected to have a mean weighted score of 2 that was between 1.5 and 2 . This meant that available materials were used.

Table 1: $\quad$ ANOVA Table for the School Types

\begin{tabular}{llllll}
\hline & Sum of Squares & Df & Means Square & F & Sig \\
\hline Between groups & 52.46 & 2 & 26.23 & 8.50 & .005 \\
Within groups & 55.52 & 18 & 3.08 & & \\
Total & 107.99 & 20 & & & \\
\hline
\end{tabular}

The ANOVA Table 1 above shows that the $\mathrm{F}$ value of 8.50 , referring to the F-test value tables of significance and the critical value were found to be 3.55 . This showed that the $f$ calculated which was 8.50 was greater than the f-critical, therefore, this showed that, in practical biology a significant relationship existed in performance amongst the three school types. This implied that, facilities availability and utilization index (as computed in the study), had a significant influence on students' performance in practical biology.

Table 2: $\quad$ Comparison of the Facilities Availability Rate

\begin{tabular}{llll}
\hline Group & Group Name & $\begin{array}{l}\text { No. of } \\
\text { Schools }\end{array}$ & $\begin{array}{l}\text { Students' Average } \\
\text { Performance }\end{array}$ \\
\hline 1 & Generally Not Available or Not Utilized & 3 & 9.37 \\
2 & Fairly Available and Utilized & 12 & 13.87 \\
3 & Generally Available and Utilized & 6 & 13.92 \\
Sig. & & 21 & 0.999 \\
\hline
\end{tabular}

Table 2 above indicates the level of performance in practical biology of the students in the three groups of the school types thus:

i. Generally available and utilized $\quad \overline{(X}=13.92)$

ii. Fairly available and utilized $\overline{(\mathrm{X}}=13.87)$

iii. Generally not available or not utilized $\quad \overline{\mathrm{X}}=9.37)$

Table 3: $\quad$ Post Hoc Test Using the F-Test Analysis

\begin{tabular}{|c|c|c|c|c|}
\hline School type name & $\begin{array}{l}\text { School type } \\
\text { comparison }\end{array}$ & $\begin{array}{l}\text { Mean } \\
\text { difference }\end{array}$ & $\begin{array}{l}\text { Std. } \\
\text { error }\end{array}$ & Sig. \\
\hline Gen & le, fairly available & -4.50 & 1.13 & .003 \\
\hline And & ally available \& Utilized & -4.55 & 1.24 & .007 \\
\hline Fairly available & nerally not available $\&$ not & 4.50 & 1.13 & .003 \\
\hline
\end{tabular}
utilized 


\begin{tabular}{lccc}
\hline Generally available \& Utilized & .005 & .878 & .998 \\
Generally available \& utilized, generally not available \& not & 4.55 & 1.24 & .007 \\
utilized & & & \\
Fairly available \& Utilized & .050 & .878 & .998 \\
\hline
\end{tabular}

The mean difference between the school types was significant at the 0.05 level.

In order to determine the effect of schools' facilities availability and utilization score on students' performance in practical Biology, the post hoc analysis was carried out in the table above.

Table 2. Indicated that the mean performance in practical biology between school types 1 and 2 and school type 3 were statistically significant in favor of school types 2 and 3 . This implied that students from school type 1 significantly performed poorer in practical biology when compared to students in school types 2 and 3. However, no significant differences existed between school types 2 and 3 as the mean difference of the students' performance in practical Biology was just .005.

\section{Discussion}

The findings of this study showed that the level of laboratory facilities in the State was low. It has also observed that the conditions of the laboratories were poor and shabby and that little or no effort had been made to improve their conditions.

This findings were important in the sense that the wide differences observed and expected in the facilities would motivate the school authorities to acquire more facilities and bring about meaningful teaching-learning environment in biology classes. The findings also highlighted the need for biology teachers to be informed about scientific methods so that they could arouse students' interest in practical activities such as field trips, excursions, educational tours, among other activities.

The findings were in agreement with Udoh (2000) who opined that absence of laboratory facilities would produce poor results among students. The same observation was made by Eshiet and Banu (1996) and Johnstone (1991). The results of the post-test showed that there was a significant relationship between laboratory facilities availability, utilization and students' performance in practical biology in schools in Gombe State.

Soruke (1982) however, discovered that insufficient equipment and facilities contributed to the poor performance in biology at senior secondary schools final-year examinations. This insufficiency could lead to lack of interest in the subject.

Abdullahi (1982) emphasised the usefulness of laboratory in the teaching-learning of biology but cautioned that laboratory activities alone without good instructional methods would still not give a good understanding of the subject. 
For teaching and learning process to succeed in biology, the use of laboratory facilities was inevitable. Proper usage of such facilities would enhance better results in practical biology examinations as well as lay a solid foundation for future studies in science.

\section{Recommendations}

The study proposed the following as recommendations.

i. $\quad$ Federal and State Ministries of Education should make available to every school standard laboratory materials and facilities needed for practicals.

ii. Policies and guidelines should be formulated for the efficient use of science laboratories for teaching and learning purpose.

iii. Ministries of Education and schools should provide separate laboratories for the sciences, and encourage their use by students. It should also ensure effective use of laboratories at all levels of education.

iv. Provisions should be made for biology practicals in the school time table, offered as double lessons.

v. Practical examinations in biology should be conducted right from SSS 1 through the final year class.

vi. Teachers and laboratory attendants should be encouraged to attend workshops and seminars in order to improve their knowledge and skills in the use of laboratory facilities.

vii. Zonal Science Laboratory Equipment Centers with the sole function of providing laboratory equipment for science teaching should be set up for the purpose of furnishing laboratories in schools.

\section{Conclusion}

Based on the corresponding analyzed, it has been shown that students were taught the theoretical lessons in biology, without experiments or practicals. The state of biology laboratory facilities in the state was low. At the end of the year, most science teachers used the laboratory for demonstrating the experiments, before the final examinations. Many of the schools did not use biology laboratory at all throughout the year, while some schools did not even consider laboratory practical lessons necessary. Most of the schools only used these facilities during the final year school exams. The study therefore, showed significant relationship in the level of availability and utilization of laboratory facilities on students' performance in biology.

\section{References}

Abdullahi, A. (1982). Science Teaching in Nigeria, Ilorin, Nigeria, Atoto Press Ltd.

Alebiosu, K. A. (2003). Readings in Science Education, Ibadan, Majestic Printers and Publishers. 
Balogun, T. A. (1986). Gender Issues in the Teaching of Science, Technology and Learning Mathematics, In S.Y. Erinosho (Ed). Perspectives of Women in Science and Technology in Nigeria, Sam Bookman Education and Communication Services, Pp. 47-61.

Eshiet, I. T. \& Banu, D. P. (1996). Improvisation in Science Teaching Philosophy and Practice, Abak, Belpot Nigeria Company.

Hofstein, A. \& Mamlok-Naaman, R. (2007). The Laboratory in Science Education: the State of the Art, Chemistry Education Research and Practice, 8 (2): 105-107. Department of Science Teaching, the Royal Society of Chemistry, the Weizmann Institute of Science, Rehovot, Israel.

Mogbo, J. O. (1992). The use of Small Scale Experiments in Teaching Science at a Period of Economic Stress, Oriental Journal of Education, 1 (1): 113-124.

Ndu, F. O. C. (1980). Planning and Organization of Practical Work in Biology SSS, Journal of STAN, 15 (3): 113-120.

Onasanya, S.A. \& Adegbija, L.V. (2007). Practical Handbook on instructional Media, $2^{\text {nd }}$ Edition, Carrphcom Publishers, Ilorin.

Oyekan, S.O. (1993). Diagnosis of Students' Weaknesses: A Conceptual Framework of Remediation of Under Achievement in Science, Journal of STAN, 25 (1 and 2).

Pritchard, R. T. (1990). General Workshop Processes and Materials, London: Hodder and Stoughton.

Sadiq, B. (2007). Fundamentals of Vocational and Technical Education, Kano, Smith Standard.

Sorunke, K. A. (1982). Biology Laboratory Facilities versus Students' Performance in Biology WAEC Examinations: A Comparative Study in Selected Secondary Schools in Kaduna State.

Udoh, A. O. (2000) Enriching Science, Technology and Mathematics Education by Mobilizing NGOs to Provide Laboratory Facilities. Proceedings of the $41^{\text {st }}$ Annual Conference of STAN, Journal of STAN, pp. 78.

Yakubu, A. (2005). Relationship between Science and Education, Un-published M.Ed. Thesis. Abubakar Tafawa Balewa University, Bauchi. 